\title{
Chronic mucocutaneous candidiasis associated with a novel frameshift mutation in IL-17 receptor alpha
}

\author{
Amiirah Aujnarain ${ }^{a *}$, Harjit Dadi ${ }^{a, b}$, and Amarilla Mandola ${ }^{a, b}$
}

\begin{abstract}
Background: Chronic mucocutaneous candidiasis (CMCC) has traditionally encompassed endocrinopathy, autoimmunity, and infection of the skin, nails, oral and genital mucosa. It is typically caused by Candida albicans, an organism that is found to be commensal in healthy individuals. To date, most patients with CMCC have mutations in AIRE or STAT1. While chronic Candida spp. infection is a feature of multiple profound T cell deficiencies, it has also been identified in rare cases involving selective immune defects, including interleukin-17 receptor A (IL-17RA) deficiency. An association between Staphylococcus aureus infections and candidiasis due to IL-17RA deficiency has recently been proposed.
\end{abstract}

Aim: We sought to identify the genetic defect in a patient presenting with recurrent oral thrush and $S$. aureus infections, but otherwise unremarkable immune workup.

Methods: Whole exome sequencing and Sanger confirmation was performed, and protein expression analysis utilized to assess the impact of the genetic aberration. A comprehensive immune workup was completed to characterize any possible deficits in his immune system.

Results: Next generation sequencing techniques identified a homozygous mutation in IL17RA, c.1696insAG, resulting in the frameshift mutation p.Q566fs. Western blot analysis confirmed the loss of IL-17RA expression.

Conclusion: We describe here a novel frameshift mutation in IL17RA. Clinically, the patient was a diagnostic challenge as he did not present with a classic CMCC phenotype. This case emphasizes the importance of genetic analysis in patients presenting with recurrent infections.

Statement of novelty: We identify a novel frameshift mutation in IL17RA in a patient presenting with recurrent bacterial and fungal mucocutaneous infections.

\section{Introduction}

Chronic mucocutaneous candidiasis (CMCC) is characterized by chronic, non-invasive Candida spp. infections of the skin, nails, and mucus membranes (Ahonen et al. 1990; Puel et al. 2011). Interleukin (IL)-17-producing $\mathrm{T}$ cells have been demonstrated to play a critical role in fighting off bacterial and fungal infections (Puel et al. 2012). The cytokine IL-17 can be further characterized into 6 different types,
IL-17 A-F, which can bind to 5 unique receptors, termed IL-17R A-E. The IL-17RA is the common subunit for all 5 members of the IL-17 receptor family (Okada et al. 2016).

Genetic aberrations which can disrupt the differentiation of lymphocytes into Th17 effector cells, or production and binding of IL-17, can result in a CMCC phenotype. These include upstream players responsible for the production of IL-17 producing cells, such as
aDivision of Clinical Immunology and Allergy, Department of Paediatrics, The Hospital for Sick Children and The University of Toronto, Toronto, ON; ${ }^{\mathrm{b}}$ The Canadian Centre for Primary Immunodeficiency and The Jeffrey Modell Research Laboratory for the Diagnosis of Primary Immunodeficiency, The Hospital for Sick Children and The University of Toronto, Toronto, ON

*Corresponding author: Amiirah Aujnarain/Doctoramiirah@gmail.com
Submitted 3 May 2019

Accepted 23 May 2019

Available online 27 May 2019

LymphoSign Journal 6:68-74 (2019)

dx.doi.org/10.14785/lymphosign-2019-0007 
the adaptor protein caspase recruitment domaincontaining protein 9 (CARD9) or transcription factors like signal transducer and activator of transcription 1 and 3 (STAT1 and STAT3) (Glocker et al. 2009; Minegishi et al. 2009; Liu et al. 2011). Furthermore, mutations in the autoimmune regulator (AIRE) gene have previously been associated with neutralizing autoantibodies against IL-17A, IL-17F and (or) IL-22, as well as syndromic CMCC due to impaired IL-17 mediated immunity (Puel et al. 2010). Downstream of IL-17RA, patients with mutations in the intracellular signaling SEF/EL-17R (SEFIR) domain of the adaptor molecule ACT1 (Zhang et al. 2014), which is crucial for IL-17 signaling, also suffer from CMCC (Boisson et al. 2013). Collectively, these findings suggest that CMCC is caused by mutations which impair the IL-17 pathway.

Given that neutralizing antibodies against IL-17 cytokines can result in CMCC phenotypes (Kisand et al. 2010; Sarkadi et al. 2014), it is thus plausible that genetic aberrations affecting IL-17 cytokines and receptors could also cause this syndrome (Puel et al. 2010). IL-17 is secreted from TH17 cells in the presence of microbial antigens, resulting in the recruitment of IL-17RA expressing neutrophils to the site of infection (Nahum 2017). This process is thought to contribute to cutaneous immunity against C. albicans and $S$. aureus infections. The clinical and immunological features of a cohort of 21 patients with autosomal recessive mutations in IL17RA was recently described (Levy et al. 2016). Affected individuals were most commonly of Middle Eastern, Japanese or South American ancestry. Interestingly, they did not present with classic CMCC-only a minority of patients had nail candidiasis. However, all patients suffered oral thrush and scalp or skin Candida spp. infections, as well as $S$. aureus skin infections. The staphylococcal infections presented in the form of folliculitis, furunculosis and pustulosis. There have also been reports of sinopulmonary infections as well as pulmonary tuberculosis (Levy et al. 2016; Okada et al. 2016).

We report here a patient who presented with recurrent oral thrush, a history of eczema complicated with recurrent superinfection of $S$. aureus and 2 episodes of sinopulmonary infections. When utilizing whole exome sequencing, we identified a novel homozygous mutation in IL17RA.

\section{Methods}

\section{Ethics}

Patient informed consent was obtained, and information collected prospectively and retrospectively from medical records (REB Protocol no. 100005598, The Hospital for Sick Children).

\section{Serum concentration of immunoglobulin and specific antibodies}

Levels serum concentrations of immunoglobulins (IgG, IgA and IgM) were measured by nephelometry and IgE concentrations determined by RIA using the IgE PRIST kit (Pharmacia Diagnostics, Dorval, QC, Canada). Serum antibodies to tetanus toxoid were measured by ELISA (Binding Site, Birmingham, UK). Serum antibodies to measles, mumps and rubella were measured using ELISA kits available from Euroimmun (Gross Groenau, Germany). Isohemagglutinin titres were determined by 2 -fold serial dilution with erythrocytes, and are reported as antiglobulin phase, the dilution at which agglutination occurs.

\section{T and B cell proliferative response}

Lymphocyte proliferative responses to the mitogen phytohemagglutinin (PHA) was performed in triplicate and compared with simultaneously stimulated normal controls, as previously described (Arpaia et al. 1994).

\section{Exome sequencing and variant calling}

Exome library preparation and sequencing was performed by The Centre for Applied Genomics (TCAG), Toronto, ON, Canada. DNA was quantified by Qubit DNA HS assay (Life Technologies, Carlsbad, CA, USA) and $100 \mathrm{ng}$ of input DNA used for library preparation using the Ion AmpliSeq Exome Kit (Life Technologies). The Ampliseq Exome library was immobilized on Ion $\mathrm{PI}^{\mathrm{TM}}$ Ion Sphere ${ }^{\mathrm{TM}}$ particles using the Ion PI Template OT2 200 Kit v3. Sequencing was performed with the Ion PI Sequencing 200 Kit v3 and Ion PI Chip v2 in the Ion Proton ${ }^{\mathrm{TM}}$ semiconductor sequencing system in accordance with the manufacturer's instructions. Alignment and variant calling were performed using Torrent Suite (v4.0) on the Ion Proton Server, using the Ion Proton ampliseq germline low stringency setting and the hg19 reference genome. The variants were annotated using an in-house annotation pipeline (Stavropoulos et al. 2016). 


\section{Sanger sequencing analysis}

Genomic DNA was extracted from isolated peripheral blood lymphocytes using the Geneaid Genomic DNA Mini Kit. Genomic DNA was amplified by PCR with specific primers designed upstream and downstream of the IL17RA gene. Sequencing was performed using GenomeLab Dye Terminator Cycle Sequencing (DTCS) Quick Start Kit (Beckman Coulter) and analyzed on CEQ 8000 Genetic Analysis System (Beckman Coulter).

\section{Western blotting}

Whole blood was collected by venipuncture and peripheral blood mononuclear cells isolated by Ficoll separation. Whole cell lysates were prepared in $1 \%$ TritonX-100 buffer and protein expression of IL-17RA analyzed by Western blotting. Primary anti-IL17RA and goat anti-rat secondary antibodies were purchased from Abcam.

\section{Results}

\section{Case report}

Our patient is a 10 -year-old male, born at term to non-consanguineous parents. The mother is healthy but the father was diagnosed with Crohn's disease as well as having cutaneous fungal infections with tinea versicolor. The patient presented originally with a history of eczema at the age of 9 months complicated with recurrent superinfection with community acquired methicillin-resistant $S$. aureus. Other infections in the first few years of life included 1 episode of pneumonia and acute otitis media. He had recurrent oral thrush and diaper rash within the first year of life that did respond to topical anti-fungal medication. Although at 3 years of age he had recurrent oral thrush and diaper rash that did not respond to topical Nystatin. At this point he had developed Candida of the nails and scalp. At this point he was started on oral fluconazole prophylaxis of 3-6 mg/kg. The patient also suffered from recurrent mouth lesions that were consistent with impetigo and responded well to topical antibiotics. He was also diagnosed with asthma, but had no evidence of endocrinopathy, or other autoimmune manifestations. He was taken off anti-fungal prophylaxis at age 9 and has not had recurrence of fungal infections since being taken off for the last 1.5 years.

\section{Immune evaluation}

Despite recurrent infections, evaluation of the immune system (Table 1) was unremarkable. Serum IgG, IgA, and
Table 1: Immune work up of patient with IL-17RA deficiency.

\begin{tabular}{|c|c|c|}
\hline Laboratory parameters & Patient & Reference range \\
\hline $\begin{array}{l}\text { White blood cell count } \\
\left(\times 10^{9} / \mathrm{L}\right)\end{array}$ & 5.7 & $5-12$ \\
\hline Neutrophils $\left(\times 10^{9} / \mathrm{L}\right)$ & 2.55 & $1.5-8.5$ \\
\hline Lymphocytes $\left(\times 10^{9} / \mathrm{L}\right)$ & 2.61 & $2-8$ \\
\hline Eosinophils $\left(\times 10^{9} / \mathrm{L}\right)$ & 0.09 & $0.02-0.5$ \\
\hline \multicolumn{3}{|c|}{ Lymphocyte subsets (cells/ $\mu \mathrm{L}$ ) } \\
\hline CD3+ & 2856 & $700-4200$ \\
\hline CD19+ & 1099 & $200-1600$ \\
\hline CD3+/CD4+ & 1799 & $300-2000$ \\
\hline CD3+/CD8+ & 916 & $300-1800$ \\
\hline NK (CD16+/56+) & 667 & $90-900$ \\
\hline PHA stimulation index & $>50 \%$ & $\begin{array}{c}>50 \% \text { of } \\
\text { patient control }\end{array}$ \\
\hline \multicolumn{3}{|l|}{ Immunoglobulins } \\
\hline $\lg G(g / L)$ & 7.2 & $5.0-14.6$ \\
\hline $\lg M(g / L)$ & 1.0 & $0.2-2.5$ \\
\hline $\lg A(g / L)$ & 0.6 & $0.3-2.0$ \\
\hline $\lg E(I U / m L)$ & 9 & $<90$ \\
\hline \multicolumn{3}{|l|}{ Vaccination titres (IgG) } \\
\hline Measles (IU/mL) & 817 (positive) & Positive \\
\hline Mumps (RU/mL) & 26 (positive) & Positive \\
\hline Rubella (IU/mL) & 60 (positive) & Positive \\
\hline Varicella & Positive & Positive \\
\hline Tetanus (IU/mL) & 0.37 & $>0.1$ \\
\hline \multicolumn{3}{|l|}{ Isohemagglutinins } \\
\hline Anti B & 32 & $>32$ \\
\hline Anti A & Not tested & - \\
\hline
\end{tabular}

IgM levels were normal, as were lymphocyte subsets. Specific antibody levels were protective to Rubella, Varicella and Tetanus as well as a good response to pneumococcal vaccine. Proliferative responses phytohemagglutinin were normal.

\section{Genetic evaluation}

Genetic testing of STAT1 and AIRE genes were negative. Subsequent whole exome sequencing and Sanger confirmation identified a novel homozygous mutation in IL17RA. The patient had a 2 base insertion in IL17RA (NM_014339.6), c.1696insAG causing a frameshift mutation (p.Q566fs) (Figure 1). The mutation was found in the SEFIR domain (amino acid residues 351-597) of IL-17RA (Figure 2) and has not previously been reported in the literature.

\section{Quantification of IL-17RA protein levels}

Western blot analysis of IL-17RA expression revealed loss of protein expression, as compared to healthy control (Figure 3). 


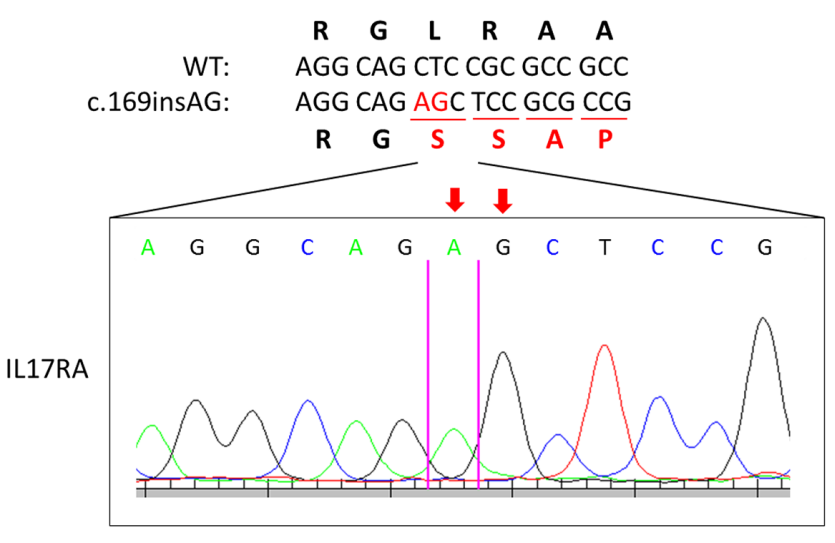

Figure 1: Novel frameshift mutation in IL17RA. Electropherogram showing the novel mutation in IL17RA (NM_014339.6), c.1696insAG, causing a frameshift mutation p.Q566fs. Insertion of bases $A$ and $G$ are identified with red arrows. Wild type (WT) and novel c.169ins AG sequences and resultant amino acids are shown.

\section{Discussion}

We report here a child presenting with recurrent S. aureus skin infections, atopy, and limited oral thrush and diaper rash. He was initially thought to have an autosomal dominant mutation given his father's history of autoimmunity; however, genetic analysis of STAT1 and AIRE were negative. Further assessment by whole exome genome sequencing revealed a novel homozygous mutation in IL17RA, encoding a crucial receptor involved in IL-17 signaling.

Patients affected with IL17RA mutations are categorized under the umbrella of CMCC, however, they do not present with classic CMCC-only a minority have skin and nail candidiasis (Levy et al. 2016; Okada et al. 2016). Our patient's recurrent $S$. aureus infections were initially thought to be secondary to a leaky skin barrier due to his atopic dermatitis. Thus, his diagnosis was delayed until years later when next generation sequencing technologies became more readily accessible.

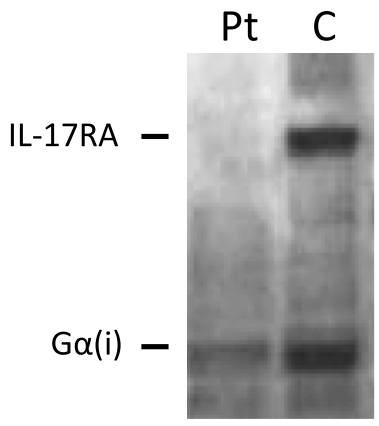

Figure 3: IL-17RA expression in patient PBMCs. Loss of IL-17RA protein expression is shown relative to healthy control, demonstrating a null phenotype.

Clinically, genetic aberrations in IL17RA are associated with susceptibility to oral thrush and scalp or skin Candida spp. infections, as well as $S$. aureus skin infections. The staphylococcal infections present in the form of folliculitis, furunculosis, and pustulosis. There have also been reports of sinopulmonary infections (Levy et al. 2016; Okada et al. 2016). Together, our patient's clinical picture fits with the reported phenotypes in the literature.

IL17RA encodes IL-17RA, a type 1 membrane glycoprotein that forms one half of a heterodimer required for IL-17A and IL-17F signaling (Gaffen 2009). The mutation identified in our patient is localized to the SEFIR domain, which is essential for interaction with ACT1 and allows for IL-17RA dependent downstream effects (Maitra et al. 2007; Ho et al. 2010). Structurefunction studies have demonstrated that the SEFIR motif is critical for IL-17A dependant activation of pathways, including MAPK, NF- $\kappa \mathrm{B}$, and C/EBP (Maitra et al. 2007). Levy et al. (2016) previously reported on a kindred with a frameshift mutation (p.N440Rfs $\left.{ }^{\star} 50\right)$ affecting the same SEFIR domain as our patient. The reported patients' clinical picture resembled our patient as they also suffered from eczema

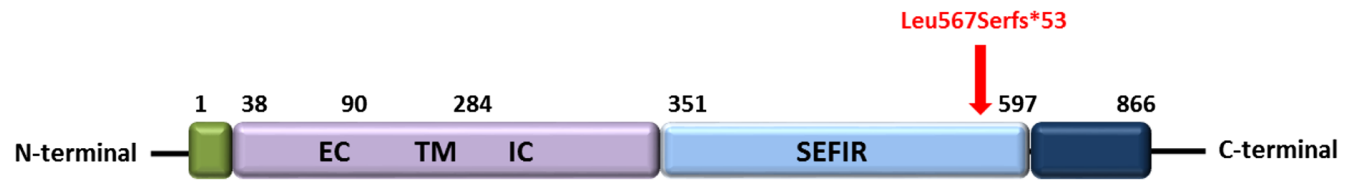

Figure 2: Schematic diagram of IL-17RA structure. The extracellular (EC), transmembrane (TM), intracellular (IC) and SEFIR (similar expression to fibroblast growth factor genes/IL17R) domains are shown, as well as the location of the mutation. 
and had skin pustulosis and folliculitis. The null mutation was associated with abolished lymphocyte responses to IL-17, as well as susceptibility to recurrent staphylococcal skin infections and bacterial respiratory infections, consistent with our patient.

IL-17A plays an important role in the clearance of S. aureus (Ishigame et al. 2009; Cho et al. 2010). Using murine models of IL-17A deficiency, Ishigame et al. (2009) showed increased susceptibility of $1117 a^{-/-}$ mice to opportunistic $S$. aureus infection compared to wild-type mice. However, intravenous administration of the bacterium revealed no difference in levels of bacterial dissemination, implying a role for IL-17A (and thus IL-17RA) in controlling local but not systemic $S$. aureus infections. In our patient, the localized infection at the skin and mucosal membranes may be partially accounted for by the dependence of keratinocytes and bronchial epithelial cells on this cytokine's protective effects. Further, IL-17A (alongside IL-17F) regulates immune function through stimulation of, among others, antimicrobial peptide production (Ouyang et al. 2008). The absence of functional IL-17RA results in abolished responses to the cytokine IL-17A (Minegishi et al. 2009). Mechanistically, this supports the chronic S. aureus skin infections that our patient suffered from.

Clinically, this case presented a diagnostic challenge. While the patient suffered from chronic oral thrush and a diaper rash, he also had eczema, skin staphylococcal infections and other oral lesions. Because both S. aureus and Candida spp. are typically commensal organisms found in healthy individuals, these infections can occur after insults to the skin, such as eczema. Therefore, it is possible that the infections in our patient were actually secondary to the initial skin lesions. Moreover, the lack of autoimmune manifestations as well as the limited fungal infection did not support the diagnosis of typical CMCC associated with AIRE and STAT1 mutations. However, this patient did ultimately have concerning features for immunodeficiency which warranted completing whole genome sequencing in an attempt to identify a genetic culprit. Specifically, in our patient with the phenotype of more than 1 recurrent and persistent infection of both Candida spp. and $S$. aureus, requiring multiple treatments of both oral and topical anti-microbial medications, and ultimately anti-fungal prophylaxis for 8 years, further genetic investigations were necessary when common culprit mutations for CMCC (AIRE and STAT1) were not identified. Together, this report highlights the need for comprehensive genetic analysis in all cases that present with recurrent fungal infections, regardless of whether the cause is thought to be primary or secondary.

In summary, we have described here a patient with recurrent CMCC and S. aureus infections due to a novel frameshift mutation in IL17RA affecting the SEFIR domain. Functionally, the absence of IL-17RA receptor expression confirms that this is a loss of function mutation.

\section{REFERENCES}

Ahonen, P., Myllarniemi, S., Sipila, I., and Perheentupa, J. 1990. Clinical variation of autoimmune polyendocrinopathy-candidiasis-ectodermal dystrophy (APECED) in a series of 68 patients. N. Engl. J. Med. 322:1829-1836. PMID: 2348835. doi: 10.1056/ NEJM199006283222601.

Arpaia, E., Shahar, M., Dadi, H., Cohen, A., and Roifman, C.M. 1994. Defective T cell receptor signaling and CD8+ thymic selection in humans lacking zap-70 kinase. Cell, 76:947-958. PMID: 8124727. doi: 10.1016/0092-8674(94)90368-9.

Boisson, B., Wang, C., Pedergnana, V., Wu, L., Cypowyj, S., Rybojad, M., Belkadi, A., Picard, C., Abel, L., Fieschi, C., Puel, A., Li, X., and Casanova, J.L. 2013. An ACT1 mutation selectively abolishes interleukin-17 responses in humans with chronic mucocutaneous candidiasis. Immunity, 39:676-686. PMID: 24120361. doi: 10.1016/j.immuni.2013.09.002.

Cho, J.S., Pietras, E.M., Garcia, N.C., Ramos, R.I., Farzam, D.M., Monroe, H.R., Magorien, J.E., Blauvelt, A., Kolls, J.K., Cheung, A.L., Cheng, G., Modlin, R.L., and Miller, L.S. 2010. IL-17 is essential for host defense against cutaneous Staphylococcus aureus infection in mice. J. Clin. Invest. 120: 1762-1773. PMID: 20364087. doi: 10.1172/JCI40891.

Gaffen, S.L. 2009. Structure and signalling in the IL-17 receptor family. Nat. Rev. Immunol. 9:556-567. PMID: 19575028. doi: 10.1038/nri2586.

Glocker, E.O., Hennigs, A., Nabavi, M., Schaffer, A.A., Woellner, C., Salzer, U., Pfeifer, D., Veelken, H., Warnatz, K., Tahami, F., Jamal, S., Manguiat, A., Rezaei, N., Amirzargar, A.A., Plebani, A., Hannesschlager, N., Gross, O., Ruland, J., and Grimbacher, B. 2009. A homozygous CARD9 mutation in a family with susceptibility to fungal infections. N. Engl. J. Med. 361:1727-1735. PMID: 19864672. doi: 10.1056/NEJMoa0810719. 
Ho, A.W., Shen, F., Conti, H.R., Patel, N., Childs, E.E., Peterson, A.C., Hernandez-Santos, N., Kolls, J.K., Kane, L.P., Ouyang, W., and Gaffen, S.L. 2010. IL-17RC is required for immune signaling via an extended SEF/IL-17R signaling domain in the cytoplasmic tail. J. Immunol. 185:1063-1070. PMID: 20554964. doi: 10.4049/jimmunol.0903739.

Ishigame, H., Kakuta, S., Nagai, T., Kadoki, M., Nambu, A., Komiyama, Y., Fujikado, N., Tanahashi, Y., Akitsu, A., Kotaki, H., Sudo, K., Nakae, S., Sasakawa, C., and Iwakura, Y. 2009. Differential roles of interleukin-17A and $-17 \mathrm{~F}$ in host defense against mucoepithelial bacterial infection and allergic responses. Immunity, 30:108-119. PMID: 19144317. doi: 10.1016/j.immuni.2008. 11.009 .

Kisand, K., Boe Wolff, A.S., Podkrajsek, K.T., Tserel, L., Link, M., Kisand, K.V., Ersvaer, E., Perheentupa, J., Erichsen, M.M., Bratanic, N., Meloni, A., Cetani, F., Perniola, R., Ergun-Longmire, B., Maclaren, N., Krohn, K.J., Pura, M., Schalke, B., Strobel, P., Leite, M.I., Battelino, T., Husebye, E.S., Peterson, P., Willcox, N., and Meager, A. 2010. Chronic mucocutaneous candidiasis in APECED or thymoma patients correlates with autoimmunity to Th17-associated cytokines. J. Exp. Med. 207:299-308. PMID: 20123959. doi: 10.1084/jem.20091669.

Levy, R., Okada, S., Beziat, V., Moriya, K., Liu, C., Chai, L.Y., Migaud, M., Hauck, F., Al Ali, A., Cyrus, C., Vatte, C., Patiroglu, T., Unal, E., Ferneiny, M., Hyakuna, N., Nepesov, S., Oleastro, M., Ikinciogullari, A., Dogu, F., Asano, T., Ohara, O., Yun, L., Della Mina, E., Bronnimann, D., Itan, Y., Gothe, F., Bustamante, J., Boisson-Dupuis, S., Tahuil, N., Aytekin, C., Salhi, A., Al Muhsen, S., Kobayashi, M., Toubiana, J., Abel, L., Li, X., Camcioglu, Y., Celmeli, F., Klein, C., Alkhater, S.A., Casanova, J.L., and Puel, A. 2016. Genetic, immunological, and clinical features of patients with bacterial and fungal infections due to inherited IL-17RA deficiency. Proc. Natl. Acad. Sci. USA, 113:E8277-E8285. PMID: 27930337. doi: 10.1073/pnas.1618300114.

Liu, L., Okada, S., Kong, X.F., Kreins, A.Y., Cypowyj, S., Abhyankar, A., Toubiana, J., Itan, Y., Audry, M., Nitschke, P., Masson, C., Toth, B., Flatot, J., Migaud, M., Chrabieh, M., Kochetkov, T., Bolze, A., Borghesi, A., Toulon, A., Hiller, J., Eyerich, S., Eyerich, K., Gulacsy, V., Chernyshova, L., Chernyshov, V., Bondarenko, A., Grimaldo, R.M., Blancas-Galicia, L., Beas, I.M., Roesler, J., Magdorf, K., Engelhard, D., Thumerelle, C.,
Burgel, P.R., Hoernes, M., Drexel, B., Seger, R., Kusuma, T., Jansson, A.F., Sawalle-Belohradsky, J., Belohradsky, B., Jouanguy, E., Bustamante, J., Bue, M., Karin, N., Wildbaum, G., Bodemer, C., Lortholary, O., Fischer, A., Blanche, S., Al-Muhsen, S., Reichenbach, J., Kobayashi, M., Rosales, F.E., Lozano, C.T., Kilic, S.S., Oleastro, M., Etzioni, A., Traidl-Hoffmann, C., Renner, E.D., Abel, L., Picard, C., Marodi, L., Boisson-Dupuis, S., Puel, A., and Casanova, J.L. 2011. Gain-of-function human STAT1 mutations impair IL-17 immunity and underlie chronic mucocutaneous candidiasis. J. Exp. Med. 208:1635-1648. PMID: 21727188. doi: 10.1084/jem.20110958.

Maitra, A., Shen, F., Hanel, W., Mossman, K., Tocker, J., Swart, D., and Gaffen, S.L. 2007. Distinct functional motifs within the IL-17 receptor regulate signal transduction and target gene expression. Proc. Natl. Acad. Sci. USA, 104:7506-7511. PMID: 17456598. doi: 10.1073/pnas.0611589104.

Minegishi, Y., Saito, M., Nagasawa, M., Takada, H., Hara, T., Tsuchiya, S., Agematsu, K., Yamada, M., Kawamura, N., Ariga, T., Tsuge, I., and Karasuyama, H. 2009. Molecular explanation for the contradiction between systemic Th17 defect and localized bacterial infection in hyper-IgE syndrome. J. Exp. Med. 206:1291-1301. PMID: 19487419. doi: 10.1084/ jem.20082767.

Nahum, A. 2017. Chronic mucocutaneous candidiasis: a spectrum of genetic disorders. LymphoSign J. 4: 87-99. doi: 10.14785/lymphosign-2017-0011.

Okada, S., Puel, A., Casanova, J.L., and Kobayashi, M. 2016. Chronic mucocutaneous candidiasis disease associated with inborn errors of IL-17 immunity. Clin. Transl. Immunology, 5:e114. PMID: 28090315. doi: 10.1038/cti.2016.71.

Ouyang, W., Kolls, J.K., and Zheng, Y. 2008. The biological functions of $\mathrm{T}$ helper 17 cell effector cytokines in inflammation. Immunity, 28:454-467. PMID: 18400188. doi: 10.1016/j.immuni.2008.03.004.

Puel, A., Doffinger, R., Natividad, A., Chrabieh, M., Barcenas-Morales, G., Picard, C., Cobat, A., Ouachee-Chardin, M., Toulon, A., Bustamante, J., Al-Muhsen, S., Al-Owain, M., Arkwright, P.D., Costigan, C., Mcconnell, V., Cant, A.J., Abinun, M., Polak, M., Bougneres, P.F., Kumararatne, D., Marodi, L., Nahum, A., Roifman, C., Blanche, S., Fischer, A., Bodemer, C., Abel, L., Lilic, D., and Casanova, J.L. 2010. Autoantibodies against IL-17A, IL-17F, and IL-22 in patients with chronic mucocutaneous candidiasis and autoimmune polyendocrine 
syndrome type I. J. Exp. Med. 207:291-297. PMID: 20123958. doi: 10.1084/jem.20091983.

Puel, A., Cypowyj, S., Bustamante, J., Wright, J.F., Liu, L., Lim, H.K., Migaud, M., Israel, L., Chrabieh, M., Audry, M., Gumbleton, M., Toulon, A., Bodemer, C., El-Baghdadi, J., Whitters, M., Paradis, T., Brooks, J., Collins, M., Wolfman, N.M., Al-Muhsen, S., Galicchio, M., Abel, L., Picard, C., and Casanova, J.L. 2011. Chronic mucocutaneous candidiasis in humans with inborn errors of interleukin-17 immunity. Science, 332:65-68. PMID: 21350122. doi: 10.1126/science. 1200439.

Puel, A., Cypowyj, S., Marodi, L., Abel, L., Picard, C., and Casanova, J.L. 2012. Inborn errors of human IL-17 immunity underlie chronic mucocutaneous candidiasis. Curr. Opin. Allergy Clin. Immunol. 12:616-622. PMID: 23026768. doi: 10.1097/ACI. 0b013e328358cc0b.

Sarkadi, A.K., Tasko, S., Csorba, G., Toth, B., Erdos, M., and Marodi, L. 2014. Autoantibodies to IL-17A may be correlated with the severity of mucocutaneous candidiasis in APECED patients. J. Clin. Immunol. 34:181-193. PMID: 24493573. doi: 10.1007/s10875014-9987-5.

Stavropoulos, D.J., Merico, D., Jobling, R., Bowdin, S., Monfared, N., Thiruvahindrapuram, B.,
Nalpathamkalam, T., Pellecchia, G., Yuen, R.K.C., Szego, M.J., Hayeems, R.Z., Shaul, R.Z., Brudno, M., Girdea, M., Frey, B., Alipanahi, B., Ahmed, S., Babul-Hirji, R., Porras, R.B., Carter, M.T., Chad, L., Chaudhry, A., Chitayat, D., Doust, S.J., Cytrynbaum, C., Dupuis, L., Ejaz, R., Fishman, L., Guerin, A., Hashemi, B., Helal, M., Hewson, S., Inbar-Feigenberg, M., Kannu, P., Karp, N., Kim, R., Kronick, J., Liston, E., Macdonald, H., MercimekMahmutoglu, S., Mendoza-Londono, R., Nasr, E., Nimmo, G., Parkinson, N., Quercia, N., Raiman, J., Roifman, M., Schulze, A., Shugar, A., Shuman, C., Sinajon, P., Siriwardena, K., Weksberg, R., Yoon, G., Carew, C., Erickson, R., Leach, R.A., Klein, R., Ray, P.N., Meyn, M.S., Scherer, S.W., Cohn, R.D., and Marshall, C.R. 2016. Whole genome sequencing expands diagnostic utility and improves clinical management in pediatric medicine. NPJ Genom. Med. 1:15012. PMID: 28567303. doi: 10.1038/ npjgenmed.2015.12.

Zhang, B., Liu, C., Qian, W., Han, Y., Li, X., and Deng, J. 2014. Structure of the unique SEFIR domain from human interleukin 17 receptor A reveals a composite ligand-binding site containing a conserved $\alpha$-helix for Act1 binding and IL-17 signaling. Acta Crystallogr. D Biol. Crystallogr. 70:1476-1483. PMID: 24816115 . doi: 10.1107/S1399004714005227. 